Scholarship Repository

University of Minnesota Law School

Articles

Faculty Scholarship

1992

\title{
GAO Report Confirms Failure of U.S. Guidelines
}

Michael Tonry

University of Minnesota Law School, tonry001@umn.edu

Follow this and additional works at: https://scholarship.law.umn.edu/faculty_articles

Part of the Law Commons

\section{Recommended Citation}

Michael Tonry, GAO Report Confirms Failure of U.S. Guidelines, 5 FED. SENTENCING R. 144 (1992), available at https://scholarship.law.umn.edu/faculty_articles/518.

This Article is brought to you for free and open access by the University of Minnesota Law School. It has been accepted for inclusion in the Faculty Scholarship collection by an authorized administrator of the Scholarship Repository. For more information, please contact lenzx009@umn.edu. 


\section{TONRY}

\section{GAO REPORT CONFIRMS FAILURE OF U.S. GUIDELINES}

\author{
Michael Tonry*
}

Like the dog that didn't bark in Conan Doyle's "Silver Blaze", thereby giving Sherlock Holmes the crucial clue, the U.S. Sentencing Commission's selfevaluation is most noteworthy for the questions it does not ask and the answers it does not provide. The available answers to the Commission's unasked questions make it clear that the guidelines have failed-that they remain deeply unpopular and mired in controversy, that they have made case processing more expensive and time-consuming, and that they have not demonstrably reduced disparities.

The silences in the Commission's report became clear when the General Accounting Office released its assessment of the guidelines' first four years. Here are three examples. First, the Commission never point-blank asked judges and other practitioners whether the current guidelines system is better than the federal sentencing system that preceded it. GAO did ask such questions, and concluded, "prosecutors generally believed that the guidelines improved the sentencing system, while most judges, defense attorneys, and probation officers on balance did not believe the guidelines were an improvement over the prior system." 1

Second, the Commission report does not examine whether the guidelines increased case processing times and costs. GAO, by contrast, reports that "the guidelines increased system workload" and that median case processing time from indictment to conviction increased by 29 percent (from 3.2 to 4.5 months), and that median time from conviction to sentencing increased by 41 percent (from 41 to 69 days). ${ }^{2}$ Along similar lines, the Commission's 1991 annual report ${ }^{3}$ shows that trial rates, after holding steady around 11 percent of dispositions from 1988 to 1990 , jumped by a third to $14.4 \%$ in 1991 .

Third, although the Commission claims its data "show significant reductions in disparity," 4 the body of the report discusses disparity analyses only for eight narrowly defined crimes, for only three of which statistically significant conclusions were reached. GAO unambiguously concluded that it is "impossible to determine how effective the sentencing guidelines have been in reducing overall sentencing disparity." 5

The Commission's silence concerning whether judges and others believe the guidelines are an improvement over what preceded them and whether the federal courts' handling of criminal cases became more or less efficient under guidelines, and its exaggerated conclusions about disparities, are

* Sonosky Professor of Law and Public Policy, University of Minnesota. striking. Those are the key questions which most observers want answered and are the bases on which the guidelines have most often been challenged.

In order to help readers reach their own conclusions, this article describes the inquiries undertaken by the Commission and GAO, methodological problems that confronted those inquiries, and conclusions reached. Not all of the subjects investigated by the Commission and GAO are considered. For example, both the Commission and GAO concluded that average sentences expected to be served nearly doubled across the board between 1984 and 1990 and that probation-only sentences became much less common, but I say no more in this article on those subjects. In the interest of a manageably narrowed focus, Parts I-III review the Commission and GAO evaluations on the three issues mentioned above-overall judgments of the guidelines, case processing efficiencies, and sentencing disparitiesand Part IV looks at the Commission's (and others') assessments of the guidelines' effects on plea bargaining and hypothesized shifts of discretion from judges to prosecutors. For sharper focus, each section begins by presenting critics' and GAO's views of the guidelines and then describes the Commission's inquiries and considers whether the Commission's self-evaluation refutes or confirms the criticisms.

Two subjects need to be addressed before looking at particular findings. First, as was also conspicuously evident in the Commission's 1991 report on mandatory penalties, the work by the Commission's staff on the self-evaluation is sophisticated and careful. Methodological and analytical problems are acknowledged. In the report's technical sections, conclusions are carefully qualified and there is little if any overclaiming. Such overclaiming as exists is in introductory and concluding sections in which Commission members presumably played much larger roles than they are likely to have played in drafting and revising technical discussions. For example, in introductory and concluding passages resistance to the guidelines is consistently understated ("guideline implementation is moving steadily forward ... . with clear indications of increasing acceptance and success $)^{\prime \prime}$ and the evidence on reduction in disparities is overstated ("the preliminary data . . show significant reductions in disparity"). ${ }^{7}$

Second, an overview of how the Commission evaluated the guidelines' effects may be a useful backdrop to the discussion that follows. The Commission combined qualitative and quantitative methods. To examine sentencing patterns and disparities over time, the Commission principally used the Federal Probation Sentencing and Supervision Information System (FPSSIS) of the Administrative Office of the U.S. Courts, "augmented FPSSIS data" from 10,000 cases sentenced in 1985, its own monitoring data, and data from the Federal Bureau of Prisons. Most comparisons of sentencing before and under guidelines compare sentences as announced and, to take account of parole release and good time, sentences "expected to be served." To examine 


\section{TONRY}

broad aggregate patterns in case processing, the Commission used data maintained by the Executive Office of the U.S. Attorneys. To examine practitioners' adaptations and reactions to guidelines, Commission staff interviewed judges, prosecutors, defense counsel, and probation officers in 12 district courts (one selected randomly from each circuit, plus one large, high-volume district chosen non-randomly). Finally, to get a broad-based indication of practitioners' opinions, the Commission conducted a national mail survey of all federal judges and assistant U.S. attorneys and of samples of private defense counsel, federal defenders, and probation officers. Hereafter, for ease of reference, these four evaluation components are referred to respectively as the "quantitative analysis," the "US Attorney data," the "12 site visits," and the "national survey."

\section{Have the Guidelines Improved \\ Federal Sentencing?}

In 1990, the Federal Courts Study Committee reported that, among federal judges and others, "There is a pervasive concern the Commission's guidelines are producing fundamental and deleterious changes in the way federal courts process criminal cases," ${ }^{8}$ a view apparently shared by most judges attending the recent Second and Eighth Circuit Sentencing Institute, and echoed by GAO in its report on the views of practitioners interviewed in four district courts. Does the Commission's selfevaluation refute those conclusions? No.

The Commission's self-evaluation, though it tries to put its findings in the best possible light, reports data consistent with GAO's. As GAO, perhaps ironically, points out, the Commission "from its interviews . . . did not report on whether the guidelines had improved the system for sentencing offenders. It asked interviewees whether the guidelines had been effective in meeting the congressionally established

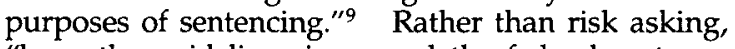
"have the guidelines improved the federal system of sentencing?" or something similar, the Commission defined the Congress's primary purpose to be the elimination of unwarranted sentencing disparity, and was then hoist on its own petard. The national survey found that only 32 percent of judges (415 of 745 answered), 11 percent of federal defenders, and 19 percent of private attorneys believed the guidelines had reduced unwarranted sentencing disparities, and bare majorities of assistant U.S. attorneys (51 percent) and probation officers (52 percent) believed disparities had been reduced. Nearly as many judges ( 28 percent) believed disparities had increased as believed them to have decreased ( 32 percent). ${ }^{10}$

An aside may be in order concerning reasons why the Commission, unlike GAO, did not inquire whether the current guidelines system is an improvement over the prior system. The Commission implies in its report that the Congress directed it to investigate disparities and other specified issues but did not authorize it to consider the overall desirability of the new system. However, Section 236(a)(1) of
Chapter II of the Comprehensive Crime Control Act of 1984 directs GAO to "compare the guidelines system with the operation of the prior sentencing and parole system," and Section 236(a)(2) directs the Commission to "submit a report ... detailing the operation of the sentencing guidelines system and discussing any problems... includ[ing] an evaluation of the impact of the sentencing guidelines on prosecutorial discretion, plea bargaining, disparities in sentencing. ..." The Commission chose to construe that broad language as limiting its evaluative focus rather than as authorizing it to undertake broad inquiries.

The closest the Commission came to asking the global question, "Is the current federal sentencing system better or worse than its predecessor," was to ask practitioners during the 12 site visits to identify problems with the guidelines. Ninety-four percent of judges described serious problems. ${ }^{11}$ Of 50 judges interviewed, 48 percent complained that the guidelines unduly reduce judicial discretion, 42 percent characterized the guidelines as inflexible, 38 percent thought they overburdened the judiciary, and 32 percent thought they overburdened the prisons. Only 3 judges (6 percent) mentioned no problems. Federal defenders and private defense attorneys made the same complaints, though more frequently, as did probation officers and prosecutors, though less frequently.

The data summarized from the Commission's self-evaluation and from the GAO study thus are consistent with earlier reports on practitioners' reactions to the federal guidelines. They were deeply unpopular when they were promulgated and they remain deeply unpopular today.

\section{Have the Guidelines Increased Case \\ Processing Times and Costs?}

The Federal Courts Study Committee reported in 1990 that 90 percent of district judges surveyed "stated that the guidelines made sentencing more time-consuming. Over half reported an increase of at least 25 percent and a third reported an increase of over 50 percent."12 GAO, as noted earlier, agreed. When GAO's data on median times from indictment to conviction and from conviction to sentencing are combined, the median time for disposition of a federal criminal case increased by 49 percent (from 137 to 204 days). Time is money in the federal courts as everywhere else; increasing the time required to dispose of the average case necessarily means that the U.S. sentencing guidelines have substantially increased the cost of handling criminal cases in the federal courts. Does the Commission's self-evaluation refute those conclusions? No.

The Commission's self-evaluation does not directly discuss case processing times and costs, but two aspects of the Commission's report indirectly examine the subject. One section, ${ }^{13}$ using the U.S. Attorney data, looks at aggregate numbers of cases filed and resolved, and plea and trial rates, and finds no discernible change in prosecutorial decisions 
attributable to the guidelines. The Commission asserted, "of particular interest is the lack of an effect associated with the guidelines on the number and proportion of guilty pleas among filed cases." 14 The only trouble with this last conclusion is that it is wrong. The Commission's 1991 annual report showed that dispositions by plea fell that year to 85.6 percent after fluctuating between 88 and 89 percent for the three preceding years. ${ }^{15}$ Presumably this represents a delayed effect of higher trial demands by offenders facing especially severe penalties. Given that the number of criminal cases in the federal courts has increased significantly since the mid-1980s, the logistical and financial implications of the increase in trial rates are ominous.

The Commission has for some years been claiming that apparently stable levels of case dispositions by plea are evidence that the guidelines have not disrupted the work of the federal courts. There was always reason to suspect that the data were misleading. After all, because the guidelines apply only to offenses committed after November 1, 1987, until very recently a large percentage of disposed cases each year have been cases not subject to the guidelines (in fiscal 1990, for example, only 65 percent of sentenced cases fell under the guidelines; by June 1991, that number rose to 74 percent). More importantly, however, increased trial rates were a foreseeable effect of the greatly increased severity of sentencing under the guidelines. A defendant facing a ten, twenty, or thirty year sentence has little reason not to take a chance on a trial and such a defendant not confined before trial has an obvious incentive to defer the nearly inevitable as long as possible.

Here, too, the claims of Commission critics are supported by GAO's findings. It is a bit odd that the Commission's self-evaluation did not look at case processing times, and accordingly that conclusions must be drawn without benefit of the Commission's own analyses. The conclusion that the guidelines have greatly increased court costs and delays is inescapable.

\section{Have the Guidelines Reduced Unwarranted Sentencing Disparities?}

We simply do not know whether implementation of the federal guidelines has reduced the prevalence of unwarranted sentencing disparities in the federal courts. GAO's conclusion, mentioned earlier, based both on examination of the Commission's analysis and its own reanalyses of Commission data, is that "limitations and inconsistencies in the data available for preguidelines and guideline offenders made it impossible to determine how effective the sentencing guidelines have been in reducing overall sentencing disparity." 16 Does the Commission's self-evaluation refute that conclusion? No.

GAO observed that "significant differences in much of the offender data available made it difficult to reliably match and compare groups of preguidelines and guidelines offenders. Preguideline offender data focused on personal information, such as socioeconomic status and family and community ties, that was supposed to be irrelevant under the guidelines in all or most cases. Conversely, most of the detailed data available on guidelines offenders, such as role in the offense, were not available for preguidelines cases." 17

The insurmountable problem that comparable data are not available on sentencing disparities before and under guidelines served as the basis for GAO's agnosticism, though it agreed with Commission analyses showing reduction in disparities for some selected offenses. GAO's own analysis showed that "unwarranted disparity continued" in relation to offenders' race, gender and employment status. ${ }^{18}$

The Commission provided three types of evidence on sentencing disparities. First, it reported findings from the national survey of judges and other federal court practitioners. Although the Commission takes solace from the finding that 32 percent of judges believed that the guidelines decreased the prevalence of unwarranted sentencing disparities, the more important finding is that 56 percent of judges believed that sentencing disparities remained the same or worsened (12 percent expressed no opinion).

Second, based on the 12 site visits, the Commission concluded that "judges, prosecutors, and probation officers generally agree that the guidelines have, in some measure, achieved one of the primary goals [reduced sentencing disparities] established by Congress."19 That practitioners "generally agree" that disparities declined "in some measure" is a highly hedged conclusion. In any case, the results of the site-visit interviews are less reliable than those from the national survey because much smaller numbers of people were involved (for example, 50 judges in the site visits compared with 415 in the national survey) and their responses are less likely to be representative. Even the national survey, however, is likely to exaggerate support for the guidelines; judges and others who refused to complete and return the Commission's survey are likelier to be hostile or disenchanted with the guidelines than are judges who cooperated.

Table 1

Percentage of Practitioners Who Believe Unwarranted Departures Have Been Reduced

\begin{tabular}{lccc}
\hline & $\begin{array}{c}\text { USSC } \\
\text { Inter- } \\
\text { views (1) }\end{array}$ & $\begin{array}{c}\text { USSC } \\
\text { Mail } \\
\text { Survey (2) }\end{array}$ & $\begin{array}{c}\text { GAO } \\
\text { Inter- } \\
\text { views (3) }\end{array}$ \\
\hline Judges & $50 \%$ & $32 \%$ & $20 \%$ \\
Prosecutors & $76 \%$ & $51 \%$ & $83 \%$ \\
Federal Defenders & $41 \%$ & $11 \%$ & $37 \%$ \\
Private Attorney & $32 \%$ & $19 \%$ & $37 \%$ \\
Probation Officer & $59 \%$ & $52 \%$ & $50 \%$ \\
\hline
\end{tabular}

Sources: (1) U.S. Sentencing Commission 1991a, table 27; (2) U.S. Sentencing Commission 1991a, table 28; (3) GAO 1992, table 3. 


\section{TONRY}

Table 1 demonstrates strikingly consistent interview and survey results from both the Commission and GAO research. Only prosecutors consistently report a belief that disparities have significantly declined under the guidelines; heavy majorities of judges and defense lawyers believe otherwise and probation officers appear about evenly split.

Third, on the basis of its quantitative analyses, the Commission reported statistically significant findings of reductions in sentencing disparities in "time expected to be served" for three of the eight narrowly defined offenses that the Commission examined.

Because of data limitations, the Commission confined its empirical analyses of disparity reduction to 4 categories of robbery (with no or moderate criminal history; with and without a weapon), two categories of embezzlement $(\$ 10,000$ to $\$ 20,000$; $\$ 20,000$ to $\$ 40,000)$, heroin trafficking $(100-400$ grams), and cocaine trafficking (500-2000 grams). Sample sizes were tiny (the pre-guidelines samples were $17,13,25,18,27,36,40$, and 44 cases; the postguidelines samples were $80,38,57,24,56,71,72$, and 81 cases). Sentences from downward departures for "substantial assistance to the government" were excluded from the analysis. For each of the eight offenses examined, sentences "pre" and "post" guidelines (both sentences announced and sentences "expected to be served") were characterized in terms of means, medians, and the range in months within which the middle 80 percent of cases fell. The breadth of the ranges of the middle 80 percent of sentences expected to be served declined for all eight offenses, though for 5 of those offenses the decline was not statistically significant. In non-jargon, the "not statistically significant" caveat means that the apparent reduction in disparity in five of the eight offenses studied could easily have resulted from random chance and have nothing to do with the guidelines.

There are, unhappily, five reasons why even these modest findings are suspect. The first two are the inherent data limitations mentioned earlier and the tiny sample sizes. The third is that the Commission ignored a major source of disparity when it excluded "substantial assistance" departures from its disparity analysis. The Commission's own process evaluation and several other studies ${ }^{20}$ suggest that "substantial assistance" motions are commonly used to permit judges to impose sentences less severe than guideline sentences that the judge and the prosecutor consider unduly harsh. In fiscal year 1991, of all disposed guideline cases, 12 percent were downward departures for substantial assistance; 21 percent of drug offense dispositions were substantial assistance departures. ${ }^{21}$ Since judges are completely free of the guidelines once a substantial assistance motion is filed, opportunity for disparity is great. Excluding those departures from the disparity analysis inevitably understates the degree of variation in sentences, especially for drug cases.

The fourth problem is that two of the offenses examined, heroin and cocaine trafficking, are offenses that have become subject to mandatory minimum 5-year sentences since the cases in the pre guidelines sample were decided. Not surprisingly, the Commission found that the median sentence imposed for both drug crimes under the guidelines was 60 months. Thus any apparent reduction in disparity is likelier to result from passage of the mandatory minimum legislation than from implementation of the guidelines.

The fifth and most important problem, however, is conceptual. "Unwarranted disparity" is not defined in the Sentencing Reform Act of 1984 and the Commission selected a self-serving definition that inevitably exaggerates disparity reduction. Most research on sentencing disparities uses multivariate analyses and mathematical models to describe sentencing patterns before and after a policy or law change. Observed differences, assuming they are statistically significant, are then attributed to the change. The Commission, instead, defined unwarranted disparities solely in terms of its own guidelines offense and criminal history characteristics.

The Commission's definition of "unwarranted disparity" is doubly misleading. First, because federal law and guidelines now set very precise standards for sentences in relation to offenses and criminal history, and the previous law had only maximum authorized sanctions and a few mandatory minimums, it would be astonishing if the new guidelines had no effect on sentencing patterns. There were previously no targets to shoot at and now there are. Unless we assume judges completely ignore the guidelines, sentences should on average be closer to the targets. Second, however, the Commission's approach might completely miss increases in disparity in relation to variables other than current offense and criminal history characteristics. Suppose, for example, that before the guidelines took effect employed offenders with dependent children typically received lighter sentences because of judges' concern for the effects of a prison sentence on spouses, children, and household stability. The guidelines, which forbid judges to take account of family status, may have made the effects of employment plus dependents less consistent than before the guidelines (because some judges continue to struggle to find ways to avoid imprisoning employed parents and others accept the Commission's policy), which would make sentencing under guidelines more, not less, disparate than sentencing under the old system. By defining and looking for "unwarranted disparities" as it did, the Commission took an impoverished look at disparity that was likely to produce a finding that disparities declined.

These methodological, measurement, and conceptual problems increased the odds that the Commission would find that unwarranted disparities have declined. That statistically significant findings of reduced disparities were achieved for only three of eight selected crimes powerfully suggests, overall, that disparities have not declined or, as GAO more cautiously concluded, that decline cannot be demonstrated. 


\section{Have the Guidelines Shifted Power to the} Prosecutor?

There is no serious question that the guidelines have strengthened the prosecutor's power to dictate or influence sentencing. Both Commission critics such as the Federal Courts Study Committee and Judge Heaney, and Commission apologists like Commissioner Ilene Nagel and Professor Stephen Schulhofer, ${ }^{22}$ have argued that the guidelines create new opportunities for prosecutors to influence sentences through their charging, bargaining, dismissal, and 5K1 motion decisions. The Federal Courts Study Committee reported: "We have been told that the rigidity of the guidelines is causing a massive, though unintended, transfer of discretion from the court to the prosecutor." 23 Judge Heaney: "The roles of the prosecutor and the probation officer in the sentencing process have been enhanced and that of the district judge diminished." 24 The only disagreement seems to be over the degree to which prosecutorial powers have been increased.

The Commission's evaluation, based on the 12 site visits, described prosecutorial practices that vary widely from court to court, and concluded from interviews that prosecutorial decisions affected the sentence that was or could have been imposed in at least 17 percent of cases. This is acknowledged to be an underestimate because it does not take account of pre-indictment negotiations or of superseding indictments or informations. ${ }^{25} \mathrm{~A}$ more recent article by Commissioner Nagel and Professor Schulhofer ${ }^{26}$ raises that estimate to 20-35 percent of cases. All of these estimates are on the low side because they depend on prosecutors signalling in some way that they have purposely manipulated the guidelines. No doubt some prosecutors, rather than openly admit evasion of the guidelines and wilful noncompliance with Department of Justice guidelines, will shelter behind legitimate rationales for sentence-affecting discretionary decisions (sufficiency of evidence, concerns for workload and optimal use of office resources, claims that a defendant has provided "substantial assistance") to circumvent guideline sentences that appear unwarrantedly severe or otherwise inappropriate.

Thus on this issue, as on all the others noted, both the Commission's self-evaluation and the GAO report confirm the contentions of Commission critics.

\section{What Are We to Conclude?}

My earlier mention of Sherlock Holmes's dog was an effort to emphasize that the Commission's self-evaluation does not address two crucial issuesoverall judgments as to whether the guidelines have improved federal sentencing and their effects on court costs and delay-and reaches no credible overall conclusion about sentencing disparities.

And yet, despite those silences, the Commission invokes the self-evaluation to make exaggerated claims about the guidelines' success. Commission chairman Wilkins, for example, in his pre- publication comments on the GAO report, claims that the selfevaluation and GAO conclude that "disparity has decreased under the guidelines" 27 and urges that GAO retitle its report "Sentencing Guidelines: Disparity Reduced, But Some Questions Remain," ${ }^{28}$ even though both the Commission and GAO reports took pains to insist that, partly for methodological reasons, as GAO put it, "neither we nor the Commission can definitively answer the central question posed by Congress regarding how effective the sentencing guidelines have been in reducing sentencing disparity." 29 Similarly, Commissioner A. David Mazzone, writing in the September 28, 1992 issue of the National Law Journal, claims that the GAO and Commission studies "firmly support a conclusion that, while there is much to be done, the new system is better than the old," even though the Commission did not solicit opinions on that global question and GAO reported that "most judges, defense attorneys, and probation officers on balance did not believe the guidelines were an improvement over the prior system."

Finally, despite the lack of GAO confirmation of its findings, the Commission, perhaps pollyannaishly, concluded that the "system is making definite, substantial progress toward successful guideline implementation .... on the whole, the guidelines system is operating relatively smoothly." ${ }^{\prime 3}$ An objective observer would, to the contrary, agree with district judge Jose Cabranes, in the July 27 issue of the National Law Journal, that the sentencing guidelines experiment is a failure, "a fact well known and fully understood . . . by virtually everyone associated with the federal justice system."

Reasonable people will differ in their explanations of why the U.S. Sentencing Commission was unable successfully to develop and implement sentencing guidelines when a number of states have succeeded. Finger-pointing, however, can serve no purpose. What is important now is to admit the failure and begin the effort to create a federal sentencing system that is efficient, fair, and even-handed.

\section{FOOTNOTES}

1 United States General Accounting Office Report to Congressional Committees. Sentencing Guidelines: Central Questions Remain Unanswered, August 1992, p. 17 (hereafter, GAO Report).

${ }^{2}$ GAO Report 1992, pp. 20, 22.

${ }^{3}$ United States Sentencing Commission. 1992. Annual Report-1991.. Table 22 (hereafter USSC 1992).

${ }^{4}$ United States Sentencing Commission. The Federal Sentencing Guidelines: A Report on the Operation of the Guideline System and Short-Term Impacts on Disparity in Sentencing, Use of Incarceration, and Prosecutorial Discretion and Plea Bargaining. December 1991, p. 419 (hereafter USSC 1991b).

${ }^{5}$ GAO Report 1992, p. 10.

${ }^{6}$ United States Sentencing Commission. The Federal Sentencing Guidelines: A Report on the Operation of the Guideline Systcoem and Short-Term Impacts on Disparity in Sentencing, Use (continued on page 183) 